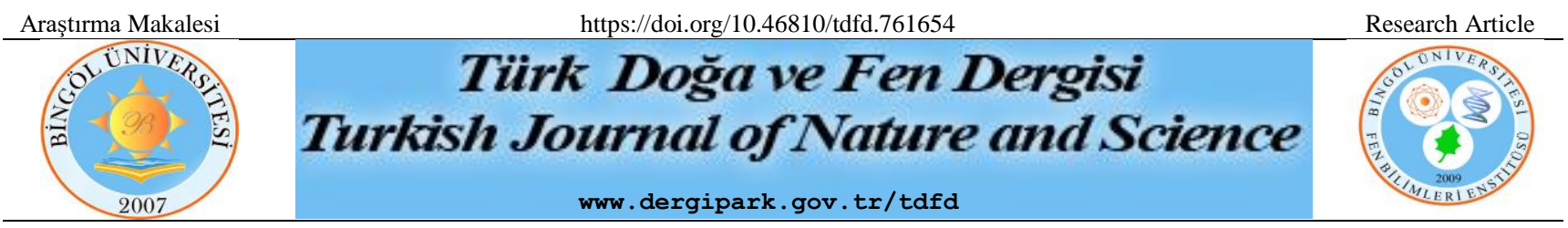

\title{
Iğdır ve Yöresinde Üretilen Balların Bazı Fizikokimyasal Özelliklerinin Belirlenmesi
}

\author{
Bayram YURT ${ }^{1 *}$, Sema ÇAKIR ${ }^{2}$ \\ ${ }^{1}$ Bingöl Üniversitesi, Mühendislik ve Mimarlık Fakültesi, Gıda Mühendisliği Bölümü, Bingöl, Türkiye \\ ${ }^{2}$ Vitalköy Eren Gıda, Kartepe, Kocaeli, Türkiye \\ Bayram YURT ORCID No: 0000-0001-5447-1586 \\ Sema ÇAKIR ORCID No: 0000-0001-7021-2242 \\ *Sorumlu yazar: byurt@bingol.edu.tr
}

(Alınış: 01.07.2020, Kabul: 16.10.2020, Online Yayınlanma: 23.10.2020)

\author{
Anahtar Kelimeler \\ Iğdır, \\ Fizikokimyasal \\ özellikler, \\ Bal, \\ Şeker, \\ Hidroksimetilfurfural
}

\begin{abstract}
Öz: Bal insan beslenmesi açısından önemli bir gıda maddesidir. Bal üretimi bakımından en uygun ülkelerden biri Türkiye'dir. Ülkemiz bal üretiminde Avrupa'da birinci sırada olup, Dünya'da ise Çin'den sonra ikinci sırada yer almaktadır. Bu çalışmada, Iğdır ve yöresinde (Kağızman, Tuzluca, Aralık) üretilen süzme çiçek ballarının bazı fizikokimyasal özellikleri belirlenmiştir. Araştırmada 30 adet süzme çiçek balı kullanılmıştır. Analiz edilen süzme çiçek ballarında briks, nem miktarı, asitlik, hidroksimetilfurfural, glukoz ve fruktoz analizleri yapılmıştır. Araştırma sonucunda ortalama fizikokimyasal değerler; Briks \% $83.30 \pm 0.97$, nem miktarı \% $15.06 \pm 0.75$, asitlik $22.64 \pm 4.16 \mathrm{meq} / \mathrm{kg}, \mathrm{pH} 4.33 \pm 0.25$, iletkenlik $0.17 \pm$ $0.15 \mathrm{mS} / \mathrm{cm}$, hidroksimetilfurfural $39.85 \pm 30.41 \mathrm{mg} / \mathrm{kg}$, fruktoz $\% 38.62 \pm 2.36$, glukoz \% $32.46 \pm 2.24$, fruktoz / glukoz oranı $1.20 \pm 0.10$ ve glukoz + früktoz miktarı $\% 71.09 \pm 3.66$ şeklinde bulunmuştur. $\mathrm{Bu}$ ortalama sonuçlar, Iğdır ve yöresinde üretilen süzme çiçek ballarının Türk Gıda Kodeksi Bal Tebliği (2012) kriterlerine genel olarak uygun olduğunu göstermiştir.
\end{abstract}

\section{Some Physicochemical Properties of Honey Produced in Iğdır and Region}

\section{Keywords}

Iğdır,

Physicochemical

properties,

Honey,

Sugar,

Hydroxymethylfurfural

\begin{abstract}
Honey is important food source for human nutrition.. Turkey is one of most suitable country for honey production. Turkey is second honey producer after China in World and is the first order at the honey production in Europe. In this research, some physicochemical properties of honey produced in Iğdır and region (Kağızman, Tuzluca, Aralık) were investigated. In research thirty strained flower honey were used. Brix, moisture content, acidity, hydroxymethylfurfural glucose and fructose analyzes were performed in filtering flower honey filtration. According to results of physicochemical analysis mean values were found as the following; Brix $83.30 \% \pm 0.97$, moisture content $15.06 \% \pm 0.75$, acidity $22.64 \pm 4.16 \mathrm{meq} / \mathrm{kg}, \mathrm{pH} 4.33 \pm 0.25$, conductivity $0.17 \pm 0.15 \mathrm{mS} / \mathrm{cm}$, hydroxymethylfurfural $39.85 \pm 30.41 \mathrm{mg} / \mathrm{kg}$, fructose $38.62 \% \pm 2.36$, glucose $32.46 \% \pm$ 2.24 , the ratio of fructose / glucose $1.20 \pm 0.10$ and the amount of glucose + fructose $71.09 \%$ \pm 3.66 . This average results showed that strained flower honey produced Iğdır and region met for Honey notification criteria of Turkish food codex (2012) in general.
\end{abstract}

\section{GíRiș}

Bal, insanoğlunun gerek beslenmesi ve gerekse de sağlığı açısından önemli fonksiyonel bir gıda maddesidir.

Bal, bitkide bulunan nektarların, bitki canlı kısım salgılarının yahut bitki canlı kısımlarında yaşamını sürdüren bitki emici böcek salgılarının Apis mellifera (bal arıs1) tarafindan toplanıp bu arının kendine ait maddelerle değiştirdiği, su muhtevasını azalttığ 1 ve petek içerisinde depolamak suretiyle olgunlaştırmaya tabi tutuğu doğal bir gida ürünüdür [1].

Mucizevi bir gıda maddesi olan bal, hoş görünümü, içerdiği farklı aroma maddeleri ve besleyiciliğiyle binlerce yıl öncesinden bu yana beğenilerek 
tüketilmektedir. Bal, zor bozulan yapısı ile kolayca saklanarak insanlık için faydalı bir gıda olmuştur. Besleyici özelliğine ilaveten yaraların iyileştirilmesinde kullanılmakta olması da balın insanlık açısından ne kadar önemli olduğunu göstermektedir. Bunların yanı sıra bal farklı dinler tarafından da önemsenmiş ve kutsal sayılmıştır [2]. Hindular, Hristiyanlar ve Müslümanlar bala önem vermiştir. Kur'an-1 Kerim'de Nahl (bal arısı) adında bir sure vardır [3].

İspanya'daki bir dağ mağarasında duvarda yer alan resimde bal toplayan k1z yer almakta olup bu resim 16.000 yıl öncesine aittir. Balı hangi zamanda, ilk kimin ve ne şekilde bulduğu bilinmemektedir [4]. Balın mucizevi gücünün farkına varan insanoğlu M.Ö. 4000 yıllarında bilinçli olarak bal üretimini gerçekleştirmiştir [5].

İnsanlar ilk olarak ağaç ve taş aralarında yaşayan arıları öldürüp ürettikleri ballarından faydalanmışlardır. Gerçek manada arıcılık insanoğlunun ağaç veya taş aralarına yuva yapmış arılara zarar vermeden balların belli bir kısmını alıp, kalanını da kovanda tutması ile olmuştur. Osmanlı kaynaklarında bazı vergilerin baldan alındığı (bal vergisi, kovan vergisi) bilinmektedir [6].

Balarısı üzerinde gerek yaşamı ve gerekse de ürünü konusunda tarihten günümüze ilgi mevcuttur. Dengeli ve sağlıklı beslenme de önemli bir yeri olan balın yanında; propolis, polen, arı sütü ve arı zehiri gibi arı ürünleri alternatif tıpta kullanılmaktadır [7].

Ülkemiz zengin bir bitki florasına sahiptir. Türkiye florası yaklaşık olarak 12000 vasküler bitki türü ile bulunduğu bölgedeki ülkeler arasında ilk sırada yer almaktadır. Bu nedenle önemli bal kaynağı olan nektarlı bitkiler yönünden de ülkemiz büyük bir potansiyele sahiptir. Nektar içeren bitkilerin bölgelere göre dağılımındaki farklılıklar nedeniyle her bölgede üretilen balların kalitelerinde de farklılıklar bulunmaktadır [8]. Türk milleti göçebe hayattan yerleşik hayat düzenine geçişle birlikte bal üretimine başlamıştır [9]. Türklerin ilk zamanlar balı "arı yağı" olarak adlandırdığı Kaşgarlı Mahmut'un açıklamalarında yer almaktadır [4]. Anadolu'nun en eski üretim etkinliklerinden birisi arıcılıktır. Arıcılık önceden sadece ailelerin gereksinimlerini karşılayacak balı üretmek için yapılırken bugün ticarette önemli bir seviyeye gelmiştir [10].

Zengin bir bitki örtüsüne sahip olan ülkemiz, çiçek balı ve çam balı üretimlerinde Dünya'da önemli bir yere sahiptir. Bölgelere göre bal çeşitliliği düşünüldüğünde kestane, çam, narenciye ve çiçek balı ülkemizin değişik bölgelerinde üretilmektedir [2].

Bal, bazı hastalıkların ve enfeksiyonların kaynağı olan mikroorganizmalar üzerinde inhibe edici etki göstermektedir [11].

Ballar kaynağına göre çiçek ve salgı balları olarak sınıflandırılmaktadır. Çiçek balları, salgı balı olan çam balı üretimlerinde Dünya bal üretiminde önemli bir yere sahip olan Türkiye zengin bir bitki örtüsüne sahiptir. Bu çeşitlilik, Türkiye'de bal üretiminde de çeşitliliğe neden olmaktadır. Ülkemizin ekolojik ve sosyo-ekonomik yapısından dolayı her tarafinda arıcılık yapılabilmektedir. Ege, Karadeniz ve Akdeniz Bölgeleri bal üretimi açısından en önemli bölgelerimizdir [2]. Türkiye'nin bal üretiminin yarısını bu 3 bölgemiz gerçekleştirmektedir. Bal üretimi açısından Ordu, Muğla, Adana, Mersin, Aydın, en önde gelen illerimizdendir [6]. Ülkemizde koloni başına elde edilen bal verimi beklenen seviyede değildir. Hâlbuki Ülkemiz bitki florası, iklim ve coğrafya bakımından arıcılık faaliyetlerine çok uygundur [12]. Orman gülü balının antioksidan ve antibakteriyel etki göstermekte, kardiyovasküler hastalıkların tedavi yöntemlerinde modern tıp yöntemlerine alternatif olarak kullanılmaktadır [13]. Denetim olmadan yetkili olmayan üreticiler tarafindan üretilen bazı özel balların kontrolsüz tüketimi ciddi bir sorun olmaya devam etmektedir [14].

Bal bileşenlerinin (karbonhidrat, su, organik asit, enzim gibi) bazıları balın olgunluğu ile ilgilidir, bazıları arılardan gelir, bazıları ise bitki kaynaklıdır [15]. Balın kimyasal içeriğini birçok faktör etkilemekle birlikte belli başlı iki faktör çok önemlidir. Bunlar nektar kaynağı ve o bölgenin rakımı, iklim yapısı ve toprağı gibi dış faktörlerdir [16].

Balın beslenme ve sağlık açısından en önemli bileşeni karbonhidratlardır [17]. Genellikle meşe ve çam ballarında glukoz ve fruktoz konsantrasyonu düşüktür. 30.6 ve $30.4 \mathrm{~g} / 100 \mathrm{~g}$ fruktoz, $23.5 \mathrm{ve} 19.7 \mathrm{~g} / 100 \mathrm{~g}$ glukoz bulunur. Bütün çiçek balları yüksek konsantrasyonda fruktoz içerir. En yüksek değerler pamuk ve ayçiçeği ballarına aittir [18].

Bal antibakteriyel etkiyi içerdiği şekerlerin osmotik basınç yapması ile sağlamaktadır. Balda bulunan lizozim enziminin de antibakteriyel etki yaptığı bilinmektedir [12]. Balın amilaz, $\alpha$-glikozidaz, glikozoksidaz, katalaz ve asit fosfotaz gibi çok sayıda enzim içerdiği bilinir. Ayrica proteaz, esteraz ve $\beta$-glikozidaz aktivitesi de bildirilmiştir [19].

Bal 1sıtıldığında veya uzun süre depolandığında monosakkarit parçalanması ya da Maillard reaksiyonu sonucu meydana gelen hidroksimetilfurfural(HMF) balda istenmeyen bir bileşendir [20]. Balda organik asitler bulunmaktadır [12]. Bal insan vücudu için yüksek derecede enerji sağlayan ve hılı biçimde bu enerjiden faydalanılan önemli bir gıdadır [21].

Birçok faydalı madde içeren bal geleneksel bir ilaç olarak bilinir. Balın terapötik etkisi giderek artmaktadır. Bazı deneylerde ve klinik şartlarda balın etkisini gösteren bilimsel kanıtlar ortaya çıkmaya başlamıştır [22]. Bal, kolay sindirilen şekerlerin derişik çözeltisi olduğundan enerji sağlık ve zindelik veren bir besindir [23]. Bal, mide bağırsak hastalıklarında, yara ve yanıkların iyileştirilmesinde antimikrobiyal ajan olarak kullanılır. Akut ve kronik mide lezyonlarına karşı gastrik koruma sağlar [22]. 
Bal, yaraların tedavisinde veteriner hekimlikte kullanılır. Yaraların iyileştirilmesinde olumlu etkileri bulunmaktadır [24]. Tatlandırıcı özelliğinin yanı sıra bal eski çağlardan beri geleneksel tıpta kullanılan doğal bir antioksidandır [25]. Bal bakteri ve mantar gelişimini önleyerek antibakteriyel ve antifungal etki göstermekte ve yaraların dezenfeksiyonunda kullanılmaktadır [26].

Bal, arıların ürettiği doğal bir maddedir. Karbonhidrat bakımından zengin olmasının yanı sıra bal sağlığımız açısından çok faydalıdır. Bu nedenle fonksiyonel bir gıda olarak kabul edilir [27].

Değişik bölgelerde üretilen balların beslendiği kaynağa göre farklı aroma ve lezzete sahip oldukları bilinmektedir. [28]. Bal fiyatlarının belirlenmesinde sahip oldukları duyusal özellikler çok önemlidir [29].

$\mathrm{Su}$ miktarı balın tanımlanmasında kullanılan başlıca kriterlerden biridir. Dolaylı olarak kuru madde miktarını gösterdiği için de önemlidir [30]. Nem miktarı \% 20 ve üzerinde olan ballarda fermantasyon riski fazladır. Bu tip ballarda depolama öncesi balın pastörize edilmesi ile balın fermantasyonu önlenebilir [31]. Belirlenen değerlerin üzerinde bulunan şeker(sakkaroz) içeriği ve suda çözünür kuru madde miktarı, ballarda tağşiş olup olmadığını anlamak için önemli bir indistir [32].

Bal pH'sı $3.20-4.50$ arasında değişen, asitli gıdalar sinıfinda yer almaktadır. Bu asidik durum nektarların olgunlaşması sırasında meydana gelen bazı asitlerden ileri gelmektedir [33]. Balın düşük pH'ya ve yüksek osmomolariteye sahip olmas1, antibakteriyel aktivitesinin sebebi olarak görülmektedir. Ayrıca baldan izole edilen antibakteriyel özellik gösteren uçucu bileşenler de bu aktivitenin diğere bir sebebi olarak gösterilmektedir [34].

Yapılan bir çalışmada doğal bal, sakaroz şurubu ile beslenen arılardan elde edilen bal, 1S1 ve asite maruz bırakılmıs sakaroz şurubu ile beslenen arılardan elde edilen bal olmak üzere 3 grup bal incelenmiștir. Sakaroz şurubu ile beslenen arılardan elde edilen balların asitlik derecesi daha düşük bulunmuştur [35]. Balın viskozitesi reolojik özellikler arasında olup birçok durumdan etkilenmektedir. Balın reolojik özellikleri vasıtasıyla proses şartları ve raf ömrü belirlenebilmektedir [36]. Ballar yüksek sicaklık derecesinde ihtiva ettiği enzimler parçalanıp bal kalitesine olumsuz etki yapmaktadır [37].

Bala üretimi esnasında ya da üretimden sonra yapılan çeşitli hileler ve ısıl işlemler balın doğal yapısını bozmakta, besin içeriğini olumsuz yönde etkilemektedir. Günümüzde en çok hile bala şeker şuruplarının katılması (tağşiş) şeklinde yapılmaktadır [38].

Sifa kaynağı olan bal, teknolojik imkânların yanlıș ve kötü kullanılması sonucu, hile yapılmasına müsait bir gıda maddesi halini almıştır. Dolayısıyla güvenli ballara ulaşmak gün geçtikçe zorlaşmaktadır. Bal üretiminde fizikokimyasal özeliklerin belirlenmesi üretilen balın standartlara uygunluğu ve bal kalitesi açısından büyük öneme sahiptir.

\section{MATERYAL VE METOT}

\subsection{Materyal}

Iğdır ve yöresinde (Merkez, Tuzluca, Kağızman) üretilen ve satışa sunulan 30 adet süzme çiçek balı numunesi analizlerimizde örnek olarak kullanılmıştır. Bal örnekleri, analizler yapılıncaya laboratuvarda uygun ortamda muhafaza edilmiştir.

\subsection{Metot}

\subsubsection{Kurılma indisi ve rutubet tayini}

Rutubet, refraktometre ile tayin edilmiştir. Bunun için, analiz numunesinden alınan yeteri kadar bal, refraktometrenin prizmaları arasına konur. Gerekli su bağlantıları kurulur ve numunenin konulduğu bölgenin sıcaklığı $20{ }^{\circ} \mathrm{C}$ ' a ayarlanmıştır. Balın optik kırılma indisi okunmuş ve çizelgede belirtilen değerlere göre nem miktarı belirlenmiştir [39].

\subsubsection{Asitlik tayini}

Tartılan bal, su ile seyreltildikten sonra, fenolftalein indikatörüne karşı, ayarlı sodyum hidroksit çözeltisi ile titrasyona tabi tutulur. Buradan, $1 \mathrm{~kg}$ baldaki asitlerin toplam mili eşdeğer sayısı hesaplanarak sonuç olarak verilmiştir.

Analiz numunesinden yaklaşık 10 gr, 0.01 gr yaklaşımla tartllarak $250 \mathrm{~mL}$ 'lik temiz, kuru bir erlene konur. Üzerine $75 \mathrm{~mL}$ su eklenip erlenin ağzı kapatılıp iyice karıştırılarak bal çözülür. Çözeltiye 4-6 damla fenolftalein çözeltisi ilave edildikten sonra, bir büretten akıtılan standard sodyum hidroksit çözeltisi ile, eşdeğerlik noktasına kadar titre edilmiştir. Eşdeğerlik noktasında, fenolftalein kırmızı renginin en az 15 saniye kaybolmadan kalmasına dikkat edilmiştir. Titrasyonda harcanan standard sodyum hidroksit çözeltisi hacmi (Vt) kaydedilir. Başka bir erlende bir şahit deney yapılarak, titrasyonda kullanılan suyun ve indikatörün harcayabileceği standard sodyum hidroksit çözeltisi hacmi (Vo) okunur. Balda mevcut asitler için harcanan sodyum hidroksit çözeltisi hacmi (V)'ni bulmak amacıyla Vt'den Vo çıkarılır [39].

Hesaplama şu şekildedir:

Numunenin asitliği (A), milieşdeğer mmol $/ \mathrm{kg}$ olarak, aşağıdaki ifade ile hesaplanır:

$\mathrm{A}=(1000 \mathrm{xMxV}) / \mathrm{m}$

$\mathrm{M}=$ Standard sodyum hidroksit çözeltisinin molaritesi $(\mathrm{mmol} / \mathrm{mL})$

$\mathrm{V}=$ Deneyde, balda mevcut asitler için harcanan sodyum hidroksit çözeltisi hacmi $(\mathrm{mL})$,

$(\mathrm{V}=\mathrm{Vt}-\mathrm{Vo})$,

$\mathrm{m}=$ Deneyde kullanılan bal numunesinin miktarı $(\mathrm{g})$ 


\subsubsection{HMF tayini}

Bal numunelerinin HMF tayini, Yüksek Performanslı Siv1 Kromotografi (HPLC) cihazı kullanılarak yapılmıştır.

Kalibrasyon materyalleri \% 99 saflıkta HMF standard kullanılarak HMF stok standardından 1, 2, 5, 7.5 ve 10 $\mathrm{mg} / \mathrm{L}$ 'lik çalışma standartları günlük hazırlanmıştır.

Örneklerin ön hazırlık aşamasında yaklaşık olarak 10 gr alınan bal örneği üzerine yaklaşık $25 \mathrm{ml}$ saf su eklenerek çalkalayıcı kullanılarak bal çözülmüştür. Çözelti, 50 ml'lik balon jojeye aktarılarak saf su ile 50 ml'ye tamamlanmıştır. $0.45 \mu \mathrm{m}$ membran filtreden süzülerek $285 \mathrm{~nm}$ dalga boyunda ölçüm yapabilen DAD dedektörlü HPLC cihazına verilmiştir. Ölçümler, $285 \mathrm{~nm}$ dalga boyunda ölçüm yapabilen DAD dedektörlü HPLC ile yapılmıştır. Tespit limiti (Detection Limit-LOD) ölçülebilir sinyal veren en düşük analit miktarına göre hesaplanmıştır. Araştırmada kullanılacak bütün kimyasal malzemeler HPLC ile analize uygun saflıkta kullanılmıştır.

Cihaz şartları :

Mobil Faz : Saf su-methanol (90/10)v/v

Analitik Kolon : C18-reversed phase (Hypersil ODS 5 $\mu \mathrm{m}, 125 \mathrm{x} 4 \mathrm{~mm}$ 250x4 mm)

Akış Oranı ve Enjeksiyon Miktarı : 1,0 ml/dk ve $20 \mu \mathrm{l}$ [40].

\subsubsection{Fruktoz ve glukoz analizi}

1 gr bal numunesi tartılmış ve üzerine yaklaşık $9 \mathrm{ml}$ saf su ilave edilerek iyice çözündürülmüştür. 0.45 mikronluk özel filtrelerden geçirildikten sonra viallere alınarak enjeksiyon yapılmıştır [41].

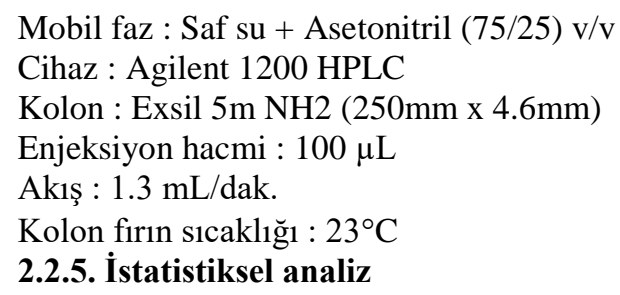

Bal örneklerinde, analiz edilen numunelere ait minimum ve maksimum değereler belirlenmiştir. Ayrıca analiz edilen numunelerin ortalama değerleri bulunmuş ve standart sapma değerleri de hesaplanmıştır.

\section{BULGULAR}

Analiz edilen bal örneklerine ait bazı fizikokimyasal analiz sonuçları aşağıda yer alan Tablo 3.1 ve Tablo 3.2 'de verilmiştir.
Tablo 3.1. Bal Numunelerinde yapılan bazı fizikokimyasal analiz sonuçları

\begin{tabular}{|c|c|c|c|c|c|}
\hline $\begin{array}{l}\text { Örnek } \\
\text { No }\end{array}$ & $\operatorname{Brix}(\%)$ & $\operatorname{Nem}(\%)$ & $\begin{array}{l}\text { Asitlik } \\
\left(\mathrm{meqkg}^{-1}\right)\end{array}$ & $\mathrm{pH}$ & $\begin{array}{l}\text { İletkenlik } \\
\left(\mathrm{Mscm}^{-1}\right)\end{array}$ \\
\hline 1 & 82,9 & 15,00 & 23,00 & 4,33 & 0,19 \\
\hline 2 & 82,4 & 15,55 & 21,00 & 4,57 & 0,13 \\
\hline 3 & 82,1 & 15,85 & 20,25 & 4,07 & 0,17 \\
\hline 4 & 82,5 & 15,50 & 21,76 & 4,33 & 0,14 \\
\hline 5 & 82,4 & 15,55 & 32,00 & 5,02 & 0,98 \\
\hline 6 & 83,7 & 14,15 & 19,50 & 4,28 & 0,11 \\
\hline 7 & 83,5 & 14,30 & 22,75 & 4,53 & 0,12 \\
\hline 8 & 83,9 & 14,25 & 20,50 & 4,01 & 0,16 \\
\hline 9 & 83,2 & 14,60 & 21,00 & 4,07 & 0,16 \\
\hline 10 & 83,2 & 14,75 & 21,00 & 4,21 & 0,22 \\
\hline 11 & 83,5 & 14,60 & 16,75 & 4,54 & 0,13 \\
\hline 12 & 81,9 & 16,00 & 27,00 & 4,13 & 0,13 \\
\hline 13 & 82,0 & 16,00 & 21,50 & 4,12 & 0,16 \\
\hline 14 & 86,4 & 13,35 & 28,00 & 4,30 & 0,14 \\
\hline 15 & 82,3 & 15,25 & 30,25 & 4,17 & 0,19 \\
\hline 16 & 82,6 & 15,35 & 25,75 & 4,18 & 0,18 \\
\hline 17 & 83,2 & 15,45 & 23,50 & 4,60 & 0,13 \\
\hline 18 & 83,7 & 14,55 & 13,75 & 4,22 & 0,14 \\
\hline 19 & 83,4 & 15,35 & 24,25 & 4,04 & 0,11 \\
\hline 20 & 84,4 & 14,25 & 21,75 & 4,69 & 0,13 \\
\hline 21 & 83,3 & 14,70 & 23,75 & 4,79 & 0,11 \\
\hline 22 & 84,2 & 14,25 & 19,75 & 4,60 & 0,13 \\
\hline 23 & 83,4 & 14,35 & 15,00 & 4,17 & 0,17 \\
\hline 24 & 82,7 & 15,55 & 25,75 & 4,41 & 0,11 \\
\hline 25 & 83,3 & 15,15 & 23,75 & 4,57 & 0,16 \\
\hline 26 & 85,0 & 15,25 & 23,50 & 4,02 & 0,13 \\
\hline 27 & 83,2 & 15,15 & 29,75 & 4,13 & 0,15 \\
\hline 28 & 82,8 & 15,35 & 19,00 & 4,19 & 0,15 \\
\hline 29 & 82,2 & 16,50 & 20,25 & 4,42 & 0,12 \\
\hline 30 & 84,5 & 16,75 & 23,50 & 4,27 & 0,13 \\
\hline Min. & 81,9 & 13,55 & 13,75 & 4,01 & 0,11 \\
\hline Maks. & 86,4 & 16,75 & 32,00 & 5,02 & 0,98 \\
\hline Ort. & 83,3 & 15,09 & 22,64 & 4,33 & 0,17 \\
\hline St. Sp. & 0,97 & 0,75 & 4,16 & 0,25 & 0,15 \\
\hline
\end{tabular}

Min: Minumum, Maks: Maksimum, Ort.: Ortalama, St. Sp.; Standart sapma

Iğdır ve yöresinde üretilen balların nem miktarı Türk Gıda Kodeksi Bal Tebliğinde belirtilen en fazla \% 20 kriterine uyumlu olup ortalama \% $15.09 \pm 0.75$ olarak bulunmuştur.

Yapılan çalıșmada elde edilen sonuçlardan asitlik miktarı da aynı şekilde Türk Gıda Kodeksi Bal Tebliğinde belirtilen en fazla $50 \mathrm{meq} / \mathrm{kg}$ limitine uyumlu olup ortalama \% $22.64 \pm 4.16$ olarak bulunmuştur.

Çalışmamızda bal numunelerinin $\mathrm{pH}$ değerleri, bir numune (5 nolu numune, $\mathrm{pH}=5.02$ ) hariç normal değerler arasında olup ortalama $4.33 \pm 0.25$ dir.

Analizlerini yaptığımız bal numunelerinde iletkenlik değerleri Türk Gıda Kodeksi Bal Tebliğinde belirtilen en fazla 0.8 Mscm-1 değerinden düşük çıkmış olup ortalama değer $0.17 \pm 0.15$ dir. 
Tablo 3.2. Bal Numunelerinde yapılan bazı fizikokimyasal analiz sonuçları

\begin{tabular}{|c|c|c|c|c|c|}
\hline $\begin{array}{l}\text { Örnek } \\
\text { No }\end{array}$ & $\begin{array}{l}\text { HMF } \\
\left(\mathrm{mg} \mathrm{kg}^{-1}\right)\end{array}$ & $\begin{array}{l}\text { Fruktoz } \\
(\%)\end{array}$ & $\begin{array}{l}\text { Glukoz } \\
(\%)\end{array}$ & $\begin{array}{l}\text { Fruktoz } \\
\text { / Glukoz } \\
(\%)\end{array}$ & $\begin{array}{l}\text { Fruktoz } \\
+ \text { Glukoz } \\
(\%)\end{array}$ \\
\hline 1 & 24,05 & 38,18 & 32,68 & 1,17 & 70,86 \\
\hline 2 & 43,10 & 38,10 & 30,25 & 1,26 & 68,35 \\
\hline 3 & 21,45 & 41,31 & 34,42 & 1,20 & 75,73 \\
\hline 4 & 55,65 & 38,78 & 30,60 & 1,27 & 69,38 \\
\hline 5 & 21,55 & 27,80 & 32,41 & 0,86 & 60,22 \\
\hline 6 & 18,75 & 40,06 & 33,05 & 1,21 & 73,11 \\
\hline 7 & 26,25 & 39,14 & 34,64 & 1,13 & 73,78 \\
\hline 8 & 19,00 & 38,69 & 30,80 & 1,26 & 69,49 \\
\hline 9 & 21,75 & 39,14 & 27,37 & 1,43 & 66,50 \\
\hline 10 & 119,7 & 38,82 & 34,12 & 1,18 & 74,21 \\
\hline 11 & 23,20 & 41,23 & 29,82 & 1,30 & 68,64 \\
\hline 12 & 22,00 & 41,09 & 35,21 & 1,17 & 76,44 \\
\hline 13 & 18,60 & 39,56 & 34,10 & 1,20 & 75,19 \\
\hline 14 & 55,10 & 38,01 & 33,57 & 1,18 & 75,13 \\
\hline 15 & 24,55 & 39,92 & 30,24 & 1,26 & 68,25 \\
\hline 16 & 47,15 & 38,13 & 33,62 & 1,19 & 73,54 \\
\hline 17 & 13,70 & 38,84 & 29,45 & 1,29 & 67,57 \\
\hline 18 & 129,00 & 37,28 & 32,73 & 1,19 & 71,57 \\
\hline 19 & 18,70 & 37,19 & 30,19 & 1,24 & 67,47 \\
\hline 20 & 26,55 & 37,81 & 32,08 & 1,16 & 69,27 \\
\hline 21 & 24,75 & 38,77 & 32,68 & 1,16 & 70,49 \\
\hline 22 & 34,00 & 38,06 & 28,02 & 1,38 & 66,78 \\
\hline 23 & 34,75 & 38,33 & 34,28 & 1,11 & 72,34 \\
\hline 24 & 69,15 & 41,64 & 33,68 & 1,14 & 72,01 \\
\hline 25 & 96,60 & 38,36 & 36,12 & 1,15 & 77,76 \\
\hline 26 & 35,65 & 39,66 & 35,94 & 1,07 & 74,31 \\
\hline 27 & 18,55 & 38,19 & 31,60 & 1,26 & 71,26 \\
\hline 28 & 26,70 & 40,09 & 31,94 & 1,20 & 70,13 \\
\hline 29 & 23,60 & 38,16 & 33,27 & 1,15 & 71,42 \\
\hline 30 & 82,00 & 38,16 & 34,99 & 1,09 & 73,15 \\
\hline Min. & 13,70 & 27,80 & 27,37 & 0,86 & 60,22 \\
\hline Maks. & 129,00 & 41,64 & 36,12 & 1,43 & 77,76 \\
\hline Ort. & 39,85 & 38,62 & 32,46 & 1,20 & 71,09 \\
\hline St. Sp. & 30,41 & 2,36 & 2,24 & 0,10 & 3,66 \\
\hline
\end{tabular}

Min: Minumum, Maks: Maksimum, Ort.: Ortalama, St. Sp.; Standart sapma

$\mathrm{Bu}$ çalışmanın en önemli analizlerinden olan HMF miktarlarında ise \% 30 miktarına tekabül eden 9 numunede ise Türk Gida Kodeksi Bal Tebliğinde belirtilen maksimum 40 ppm sınırı dışında kalmıştır. \% 70 numunemiz HMF açısından kabul edilebilirlik değerleri içerisindedir. Ortalama HMF miktarları 39.85 $\mathrm{ppm} \pm 30.41$ olarak bulunmuştur.

Ballarda en önemli kalite kriterlerinden olan Fruktoz ve Glukoz toplamı ve oranları Türk Gıda Kodeksi Bal Tebliğinde belirtilen değerlerle uyum içerisindedir. Fruktoz + Glukoz oranı tebliğde belirtilen minimum \% 60 değerlerinin üzerinde olup ortalama \% 71.09 \pm 3.66 olarak tespit edilmiştir.

Aynı şekilde Fruktoz / Glukoz oranı da bir numune dışında tebliğde belirtilen 0.9-1.4 arası değerlerde olup ortalama $1.20 \pm 0.10$ olarak bulunmuştur.

\section{SONUÇ}

Çalışmamızda bulunan nem miktarı değerleri daha önce yapılan çalışmalarda elde edilen sonuçlarla benzerlik arz etmektedir [42][43][44]. Araştırmamızda tespit ettiğimiz briks miktarları yapılmış araştırmalarda elde edilen sonuçlarla uyumluluk göstermektedir [42][45][46]. Bu çalışmada tespit edilen $\mathrm{pH}$ değerleriyle daha önceki çalışmalarda tespit edilmiş $\mathrm{pH}$ değerlerinin benzer olduğu görülmektedir [43][47][48]. Çalışmamızda bulunan iletkenlik değerleri ve hidroksimetilfurfural değerleri yapılmış çalışmadaki değerlerle benzerlik arz etmektedir [49]. Araştırmamızda tespit edilen glukoz, fruktoz oranı, toplamı ve birbirine oranı yapılmış çalışmalarda bulunan sonuçlarla uyumluluk göstermektedir [43][50][51].

Yapılan bu çalışmada elde edilen sonuçlar literatürlerde geçen araştırmacılarınki ile genel olarak benzerlik göstermektedir. Her yörenin bal kalitesine etki eden şartları farklı olduğundan bazı çok az sayıdaki sonuçlarda farklılıkların olması beklenilen bir durumdur. $\mathrm{Bu}$ çalışma daha önce yapılan çalışmalara kıyastan ziyade bu bölgede üretilen balların standartlara uygunluğunun kontrolü amaçlanmıştır.

HMF açısından dokuz adet bal numunesinin (\%30) tebliğde belirtilen maksimum değerden yüksek çıkması süzme aşamasında 1sı uygulanması ve uygunsuz depolamadan kaynaklanmaktadır. HMF'nin yüksek çıkması bal üreticilerinin bal üretimi konusunda yeterli bilgiye sahip olmadıkları kanaatini doğurmuştur. HMF'nin sağlıklı beslenme açısından bir risk olduğu göz önünde bulundurulduğunda bal üreticileri bu hususta eğitim çalışmalarıyla bilinçlendirilmelidir.

Yapılan analizlerde sadece 1 adet numunede gerek şeker oranları ve gerekse de $\mathrm{pH}$ ve iletkenlik açısından olumsuzlukların olduğu göze çarpmaktadır. Bu durumun muhtemel en önemli sebebi bal hilelerinden olan tağşiştir.

$\mathrm{Bu}$ sonuçlar bize ülkemiz bal üretiminde ön planda olmayan yörelerimizde düşük miktarda bal üretimi yapan arıcıların, gerek ailesi ve gerekse de tanıdıkları için bal ürettiklerinden balda taklit ve tağşiş yapmadıklarını düşündürmektedir. Iğdır ve yöresinde yapılmış bu ilk çalışma, gelecekte yapılacak çalışmalara katkı sağlayacaktır.

\section{Teşekkür}

Bu çalışmaya destek veren Iğdır Üniversitesi Bilimsel Araştırma Projeleri Koordinasyon Birimine teşekkür ederiz.

\section{KAYNAKLAR}

[1] Türk Gıda Kodeksi Yönetmeliği Bal Tebliği. Tebliğ No: 2012/58. Resmi Gazete. [İnternet]. 2012. [Cited 2012 Dec 25]. https://www. resmigazete.gov.tr/2012/07/20120727-12.htm

[2] Mortaş, M., Yazıcı, F., Dervişoğlu, M. Balın Samsun ve Karadenizdeki Yeri. Samsun Sempozyumu, 2011. 13-16 Ekim, p. 351-354.

[3] Tunçel, H. Türkiye'de 1966 -1986 Yılları Arasında Arıcılığa Genel Bir Bakış. Türkiye Coğrafyası 
Uygulama ve Araştırma Merkezi Dergisi, 1992. $1: 3$. p. 51-54.

[4] Sönmez, B., Balın İnsan Sağlığındaki Yeri ve Önemi. Uludağ Bee Journal. 2004. Ağustos. p.127130.

[5] Demirci, M. Beslenme. In: Karbonhidratlar. Gida Teknolojisi Derneği Yayın No:44. 2005. p. 35-52.

[6] Arıcillk. [İnternet]. 2013. [cited 2013 jun 13]. http://www.ordutb.org.tr/admin/dosya/aricilik_son( 2013)(1).pdf

[7] Kumova, U., Korkmaz A., Avcı, B.C., Ceyran G. Önemli Bir Arı Ürünü: Propolis. Uludağ Bee Journal, 2002. 2:2,10-23.

[8] Terzi, E.,. Bilecik ve Çevresinde Üretilen Ballarda Bulunan Polenlerin Araştırılması. Yüksek Lisans Tezi. 2009. Anadolu Üniversitesi Fen Bilimleri Enstitüsü Biyoloji Anabilimdalı, p: 77.

[9] Dinç, M.. Anadolu Sahasında Arıcılık ve Bal Üretimi Çerçevesinde gelişen İnanç ve Gelenekler Konusunde Bir İnceleme. International Periodical For The Languages, 2013. 8:1149-1156.

[10] Kekeçoğlu, M.,. Balarısı, Biyoçeşitlilik ve Koruma Çalışmaları. Arıcılık Araştırma Dergisi. 2009; 2:1, 3-5.

[11] Özmen, N., Alkın, E. Balın Antimikrobiyal Özellikleri ve İnsan Sağlığı Üzerine Etkileri. Uludağ Arıcılık Dergisi. 2006; 6:4, 155-160.

[12] Kekeçoğlu, M., Gürcan, E.K., Soysal, M.İ.. Türkiye Arı Yetiştiriciliğinin Bal Üretimi Bakımından Durumu. Tekirdağ Ziraat Fakültesi Dergisi, 2007; 4(2).227-236.

[13] Çeter, T., Güney, K. Orman Gülü ve Deli Bal. Uludağ Bee Journal . 2011; 11(4), 124-129.

[14] Öztürk, B., Çağlar, F.N., Kaya, B., Uysal, D., Karabağ, T.. Mad Honey intoksication in Three İndividual Patients Admitted to the Emergency Department. Istanbul Med J. 2014;15(1), 196-198.

[15] Anklam, E. A review of the analytical methods to determine the geographical and botanical origin of Honey. Food Chemistry. 1998; 63(4). 549-562.

[16] Uçkun, O.. Narenciye ve Geven Ballarının Aroma ve Aroma Aktif Bileşiklerinin Belirlenmesi. 2011. Yüksek Lisans Tezi, Çukurova Üiversitesi Fen Bilimleri Enstitüsü

[17] Karadal, F., Yıldırım, Y. Balın Kalite Nitelikleri, Beslenme ve Sağlık Açısından Önemi. Erciyes Üniv Vet Fak Derg. 2012; 9(3) 197-209.

[18] Poyrazoglu, E.S., Haroun, M.I., Konar, N., Hospolat, I., Artık, N., 2012. Sugars Profiles and Contents of Turkish Honeydew and Floral Honeys. International Conference on Environment. Agriculture and Food Sciences. 59-62.

[19] Yılmaz, H., Şakıroğlu, H., Kührevioğlu, İ. Catechol oxidase activity in honey from Eastern and Southeastern Anatolia. Journal of Apicultural Research. 2003; 42(2), 22-23.

[20] Chernetsova, E.S., Morlock, G.E.. Assessing the capabilities of direct analysis in real time mass spectrometry for 5-hydroxymethylfurfural quantitation in honey. International Journal of Mass Spectrometry. 2012; 3(4), 22-32.

[21]Mesleki eğitim ve öğretim sisteminin güçlendirilmesi projesi. Gıda Teknolojisi, Bal
Analizleri. [İnternet]. 2012. [Cited 2012 Dec 27]. http://megep.meb.gov.tr/mte_program_modul/mod uller_pdf/Bal\%20Analizleri\%201.

[22] Al-Mamary, M., Al-Meeri, A., Al-Habori, M. Antioxidant activities and total phenolics of different types of honey. Nutrition Research. 2002; 86(2), 1041-1047.

[23] Orak, H.,. Yurdumuzun Değişik Yöre Ballarının Bileşimi Kristallenme nedenlerinin Araştırılması. Doktora Tezi, 1986; İstanbul Üniversitesi Mühendislik Fakültesi Kimya Bölümü Besin Kimyası Anabilimdalı.

[24] Çelimli, N. Veteriner Hekimlikte yara tedavisinde bal kullanımı. Bee J. February 2010; 11 (3): 85-91, Bursa.

[25] Kassim, M., Mansor, M., Suhaimi, A., Ong, G., Yusoff, K.M.. Gelam Honey Scavenges Peroxynitrite During the Immune Response. Int. J. Mol. Sci. 2012;13(1), 12113-12129.

[26] Bal Hakkında. [İnternet]. 2013. [Cited 2013 May 02]. http://www.balder.org.tr/bal_hakkinda.htm

[27] Silici, S., Soylu, M., Honey and Glycemic Index. Turkish Journal of Agriculture. 2015; 3(5), 283293.

[28] Sunay, A.E., Akdoğan, G., Boyacıoğlu, D.,. Balın Bölgelere Göre Duyusal Farklılıklarının Belirlenmesi. Türkiye 10. Gida Kongresi,2008; p. 829-832.

[29] Sunay, A.E., Boyacıoğlu, D. Türk Ballarında Tanımlayıcı Analiz ve Profil Testi. Türkiye 9. Gıda Kongresi, 2006; p.35-38

[30] Çınar, S.B., Ekşi A. Türkiye'de Üretilen Çam Balının Kimyasal Profili. Gida. 2012; 3 (3): 149156.

[31] Bal Sektörü İçin İyi Hijyen Uygulamaları Rehberi. Rehber No:1. [İnternet]. 2012. [Cited 2012 July 13].https://duzce.tarimorman.gov.tr/Belgeler/GIDA /Bal_Sektoru.pdf

[32] Haroun, M.I.. Türkiye'de Üretilen Bazı Çiçek ve Salg1 Ballarının Fenolik Asit ve Flavonoid Profilinin Belirlenmesi. Doktora tezi, 2006; Ankara Üniversitesi Fen Bilimleri Enstitüsü

[33] White, J. Composition of honey. In Crane, E (ed) honey: a comperhensive survey. Heinemann, 1975. London. 157-206.

[34] Bogdanow, S. Nature and Origin of the Antibacterial Substances in Honey. Lebensm.Wiss. u.-Technol. 1997;30(1), 748-753.

[35] Özcan, M., Arslan, D., Sert, D.,. Effect of İnverted Saccharose on some Properties of Honey. Food Chemistry. 2005; 99, 24-29.

[36] Kayacier, A., Karaman, S.. Balların Reolojik Karakterizasyonu. Türkiye 10. Gıda Kongresi, 2008; p. 285-288.

[37] Polat, G.,. Farklı Lokasyon ve Orijinlere Sahip Balların Reolojik, Fizikokimyasal Karakteristikler ve Mineral İçeriklerinin Belirlenmesi. Yüksek Lisans Tezi, 2007. Selçuk Üniversisitesi Fen Bilimleri Enstitüsü

[38] Tosun, M., Keleş, F. Bala Sakaroz Şurubu Katılarak Yapılan Hileleri Belirleme yöntemlerinin Araştırılması. Türkiye 10. Gıda Kongresi, 2008; p.51-54 
[39] TS 3036. Bal standard1. [İnternet]. 2002. [Cited 2013 Jen 07]. http://www.balmer.com/Files/files/dokumanlar/tse-standarditse036bal/TSE\%20\%20Standard\%C4\%B1\%20\%20Bal.pdf

[40] Küplülü, Ö. Süzme Ballarda Muhafaza Sicaklığının HMF Değeri ve Diastaz Aktivitesi Üzerine Etkisi. Ankara Üniversitesi Bilimsel Araştırma Projesi Kesin Raporu. 2010..

[41] TS 13359. Bal-Fruktoz, Glukoz, Sakaroz, Turanoz ve Maltoz Muhtevası Tayini- Yüksek Performanslı Siv1 Kromatografisi (HPLC) Metodu, [İnternet]. 2008; [Cited $2013 \quad$ Feb 07]. https://intweb.tse.org.tr/standard/standard/Standard. aspx?0811180511151080511041191101040550471 05102120088111043113104073097106122089121 097102053048082055.

[42] Tosun, M., Keleş, F.. Balda Yapılan Hileleri Belirleme Yönetemlerinin Uygunluğunun Araştırılması. Doktora Tezi, 2004; Atatürk Üniversitesi Fen Bilimleri Enstitüsü, Erzurum.

[43] Şengül, M., Şengül, M., Dodoloğlu, A.. Erzurum'da üretilen balların fiziksel ve kimyasal özellikleri. Türkiye 9. G1da Kongresi, 2006; S.863-867.

[44] Kenjerić, D., Mandić, M.L., Primorac, L, Bubalo, D., Perl, A.. Flavonoid profile of Robinia honeys producted in Croatia. Food Chemistry, 2007; 102, 638-690.

[45] Silva, L.R., Videira, R., Monteiro, A.P., Valentão, P., Andrade, P.B.. Honey from Luso region (Portugal): Physicochemical characteristics and mineral contents. Microchemical Journal. 2009; 93, 73-77.

[46] Anupama, D., Bhat, K.K., Sapna, V.K. Sensory and physico-chemical properties of commercial samples of honey. Food Research International, 2003; 36, 183-191.

[47] Devillers, J., Morlot, M., Pham-Delégue, M.H., Doré, J.C. Classification of monofloral honeys based on their quality control data. Food Chemistry, 2004; 86, 305- 312.

[48] Saxena, S., Gautam, S., Sharma, A. Physical, biochemical and antioxidant properties of some Indian honeys. Food Chemistry. 2010;118, 391397.

[49] Batu, A., Küçük, E., Çimen M.. Doğu Anadolu ve Doğu Karadeniz Bölgeleri Çiçek Ballarının Fizikokimyasal ve Biyokimyasal Değerlerinin Belirlenmesi. Gıda Teknolojileri Elektronik Dergisi, 2013; 8(1), 52-62.

[50] Chakir, A., Romane, A., Marcazzan, G.L., Ferrazzi, P. Physicochemical properties of some honeys produced from different plants in Morocco. Arabian Journal of Chemistry, 2011;1-9.

[51] Güler, Z. Doğu Karadeniz Bölgesinde üretilen balların kimyasal ve duyusal nitelikleri. Gida dergisi.2005; 30(6), 379-384. 